\title{
Meia noite em paris: a perda da aura na modernidade e a exaltação do passado
}

Resumo: Encenado na Paris de 2010, o filme de Woody Allen, Meia Noite em Paris (Midnight in Paris, 2011) é um romance nostálgico, cujo tema central é a nostalgia do homem moderno em relação a um passado que ele não pode viver e que acredita ser melhor que seu presente. Tal tendência pode ser considerada uma constante na realidade atual, em que os indivíduos sentem-se cada vez mais alheios à sociedade em que vivem. É o "passadismo" retratado no filme, consequência de uma vontade comum: de viver em um período no qual eram compartilhadas experiências, ao invés de meramente desfrutadas vivências; onde as pessoas não sentiam-se estranhas em seu próprio tempo, vivendo a angustia de ser apenas mais um em meio à multidão; e, principalmente, uma época em que a aura da obra da arte, sua essência e autenticidade esteve viva, presente e real.

Palavras-chave: passado; nostalgia; perda da aura; modernidade.

\section{Introdução}

O garçom atende fregueses sentados em mesas ao ar livre, enquanto turistas atravessam ruas encantados pelas peculiaridades de construções e monumentos históricos, parques verdes e belos chafarizes. Paisagens iluminadas encantam os olhos e o coração: são lagos, rios, pontes e as adoráveis ruelas que recortam a cidade, deixando-a com características inconfundíveis. Uma instantânea garoa faz com que as pessoas apressem o passo, abram charmosas sombrinhas e vistam suas capas de chuva. É a capital da França, no ano de 2010, cenário que abre o filme escrito e dirigido por Woody Allen, Meia Noite em Paris (Midnight in Paris, 2011), um romance nostálgico, cujo tema central foca no saudosismo do homem moderno em relação a um passado que ele não pode viver e que acredita a todo custo ser melhor que seu presente.

O personagem protagonista da trama, Gil Pender, largaria a qualquer momento a vida enfadonha de roteirista, que leva ao lado da noiva Inez, nos Estados Unidos. Com o casamento marcado, ambos estão em Paris a passeio, acompanhando os pais de Inez em uma viagem de negócios. Gil almeja ser um escritor de romances, viver em Paris e desfrutar a tranquilidade de uma vida cheia de inspirações. Entretanto, sua grande fascinação é o passado. "Imagine esta cidade nos anos 20. Paris nos anos 20, na chuva. Os artistas e os escritores...", argumenta com a noiva, na cena inicial do filme. Inez, entretanto, não compartilha do sonho do noivo, levando uma vida baseada em aparências e almejando viver em Malibu (EUA), após o casamento, pois alega que não conseguiria viver fora do seu país. "Você está apaixonado por uma fantasia", rebate aos devaneios de Gil.

Um caricato modelo de família de classe alta norte americana, Inez e os pais John e Helen são completamente apegados aos bens financeiros, objetos supérfluos e ideais sobre os quais se recusam a entrar em discussão. Acreditam ser uma "pechincha" pagar 20 mil dólares por cadeiras de praia, por exemplo. O impulsivo Gil não recebe a devida aprovação para o 
casamento, vinda dos pais de Inez, e o casal visivelmente sente dificuldades em se entender, principalmente no que diz respeito ao futuro, entretanto, acreditam estar apaixonados.

A exaltação do passado e a nostalgia de um tempo que não é sua realidade é um dos temas centrais do filme. Tal tendência pode ser considerada uma constante na realidade moderna, em que os indivíduos sentem-se cada vez mais alheios à sociedade em que vivem, almejando viver em outro período, onde acreditam que havia uma realidade mais alegre, compartilhada, criativa, enfim, mais feliz que a sua própria.

\section{A perda da capacidade de compartilhar experiências}

De acordo com o autor Walter Benjamin, a sociedade moderna vive um momento em que se perdeu a capacidade de compartilhar experiências de vida. Com o advento da tecnologia, a disseminação de informação substituiu o intercâmbio de experiências e até o próprio convívio e discussões em grupo. "[...] a arte de narrar está em vias de extinção. São cada vez mais raras as pessoas que sabem narrar devidamente" (BENJAMIN, 1994, p.197). Benjamin não se refere ao narrador enquanto categoria narrativa de fato, mas a um nato contador de histórias, enraizado na oralidade, tal como se caracteriza o personagem de Gil. O autor afirma:

É como se estivéssemos privados de uma faculdade que nos parecia segura e inalienável: a faculdade de intercambiar experiências [...] Uma das causas desse fenômeno é óbvia: as ações da experiência estão em baixa, e tudo indica que continuarão caindo até que seu valor desapareça de todo. (BENJAMIN, 1994, p. 198).

As pessoas perderam a tradição de viver experiências e transmiti-las. Tanto tradições e cultos quanto relatos de viagens e novos conhecimentos. "[...] o narrador é um homem que sabe dar conselhos. Mas, se dar conselhos parece hoje algo de antiquado, é porque as experiências estão deixando de ser comunicáveis" (BENJAMIN, 1994, p.200). De acordo com o autor, "o conselho tecido na substância viva da existência tem um nome: sabedoria. A arte de narrar está definhando porque a sabedoria - o lado épico da verdade - está em extinção" (BENJAMIN, 1994, p.200-201).

De acordo com o autor, esse processo tem definhado cada vez mais, com a ascensão do capitalismo. Este fenômeno "ao mesmo tempo dá uma nova beleza ao que está desaparecendo" (BENJAMIN,1994, p.201). É o que fica evidente no filme Meia Noite em Paris. O saudosismo do que tem desaparecido, deste compartilhamento de experiências, considerando sempre que viver no passado era melhor que a realidade atual. Benjamin argumenta:

Como disse Pascal, ninguém morre tão pobre que não deixe alguma coisa atrás de si. Em todo caso, ele deixa reminiscência, embora nem sempre elas encontrem um herdeiro. O romancista recebe a sucessão quase sempre com uma profunda melancolia (BENJAMIN, 1994, p .212). 
A melancolia é, em si, uma característica muito presente na realidade do indivíduo moderno. Ressaltar o passado e os tempos idos como um período melhor que o seu é uma tendência que cada vez mais se acentua no interior do indivíduo, visto que o que existe é uma desilusão para com o tempo em que se vive. Em um dado momento do filme, Gil e Inez encontram com um casal de amigos dela, Paul e Carol, com quem Inez passa a sair em diferentes programações. Em uma visita ao Palácio de Versalhes, Inez menciona que o noivo é uma pessoa que vive no passado, "que pensa que seria mais feliz se vivesse numa época anterior". Paul, então, argumenta que a Paris dos anos 20, realidade sonhada por Gil, de fato não teria problemas como aquecimento global, nem televisão, atentados suicidas, armas nucleares e cartéis de drogas. Em meio à conversa, Paul define: "[...] esta falácia é chamada de pensamento da Era de Ouro [...] a noção errada de que uma época diferente é melhor do que aquela em que vivemos. É uma falha da imaginação romântica de quem tem dificuldade em enfrentar o presente".

\section{Viagem no tempo}

É quase meia noite em Paris, quando Inez resolve sair para dançar com o casal de amigos Paul e Carol. Gil, entretanto, sente-se deslocado em meio ao grupo e prefere caminhar pelas ruas da cidade. Em um dado momento, ele percebe que está perdido e não consegue encontrar o hotel em que estão hospedados. Gil senta-se em frente à uma pequena igreja e ouve o badalar do sino anunciar a chegada do próximo dia. É meia noite em Paris.

Quando Gil se dá conta, um carro modelo Pegeout antigo, da década de 1920 estaciona em sua frente. As pessoas no interior do veículo o convidam para entrar. Confuso e um tanto alcoolizado, Gil decide aceitar o passeio e é então transportado imediatamente ao tempo onde sempre sonhou estar: a década de 20, com todo o seu glamour, grandes festas e muitos dos intelectuais de quem cresceu lendo histórias, admirando obras e ouvindo músicas.

Gil não consegue acreditar no que está acontecendo. Encontra-se com memoráveis figuras, como Zelda e Scott Fitzgerald, Joan Cocteau, Ernest Hemingway, Gertrude Stein, Salvador Dalí, Cole Porter, entre outros, em um período no qual grandes gênios das artes viviam em Paris. Mulheres dançam com seus vestidos de franjas e chapéus clássicos, enquanto Gil cria amizades com os escritores que tanto admira e consegue, inclusive, que leiam o esboço do romance que ele está escrevendo.

Quando repentinamente o personagem volta à realidade, tenta contar, no dia seguinte, a aventura vivida à noiva Inez. Ele tenta leva-la consigo para "viajar no tempo", porém, ela não tem paciência de esperar até a meia noite, em frente à igreja. Quando Inez vai embora, o carro reaparece e Gil novamente embarca no passeio dos seus sonhos.

E assim, enquanto sua noiva vive um romance com o amigo Paul, Gil aproveita as noites parisienses em um tempo e espaço onde sempre sonhou estar. Até que, em uma noite nos anos 20, ele conhece a jovem Adriana. Amante de pintores famosos, como Pablo Picasso, Adriana se diz uma amante do passado, característica com que Gil imediatamente se identifica. "Para mim, La Belle Epóque em Paris seria perfeito [...] Toda sensibilidade, os postes de luz, os quiosques, cavalos e carruagens", suspira a jovem.

Apaixonados, Gil e Adriana sentam-se em frente à um café, em mais uma noite na década de 20, quando subitamente uma charrete encosta em frente e os convida para entrar. Os dois são então transportados à década de 1890, o início da Belle Epóque francesa. Adriana sente-se maravilhada ao encontrar personalidades e artistas daquele período, tal como sentia- 
se Gil, quando viajava à 1920. Ao encontrarem, em um cabaré, os pintores Paul Gauguin e Edgar Degas, ouvem o pensamento destes artistas, os quais afirmam seguramente que a geração em que vivem "é vazia e não tem imaginação [...] Melhor seria ter vivido durante a Renascença". Adriana discorda, dizendo que a o momento em que estão é a Idade do Ouro. E é ali que ela decide ficar.

O presente de Adriana, que tanto encanta Gil, é, para ela, enfadonho. Neste momento, Gil se dá conta de que nenhuma geração está de fato contente com o período que vive. "É isso que o presente é. Um pouco insatisfatório porque a vida é um pouco insatisfatória", reflete.

De volta à realidade, Gil resolve ficar em Paris e separar-se da noiva Inez, com quem percebe que não tem quase nada em comum e cujo casamento, obviamente, seria um fracasso. Ao final do filme, ele encontra-se casualmente na rua com Gabrielle, uma jovem vendedora de discos, com quem sai a caminhas pelas ruas da Paris dos anos 2010.

\section{Perda da aura}

De fato, enfrentar o tempo em que se vive requer readaptar-se constantemente a uma sociedade mutável, que muitas vezes exaure o ser humano em uma busca constante pelo novo. Acaba se perdendo o valor que é antigo e os mais experientes são tidos como ultrapassados. São os novos valores dos indivíduos, impostos pelo sistema, de uma forma coletiva e serial. Para Benjamin, o que se perde é a valorização do próprio ato de se transmitir histórias e experiências:

\footnotetext{
Quem encontra ainda pessoas que saibam contar histórias como elas devem ser contadas? Que moribundos dizem hoje palavras tão duráveis que possam ser transmitidas como um anel, de geração em geração? Quem é ajudado, hoje, por um provérbio oportuno? Quem tentará, sequer, lidar com a juventude invocando sua experiência? (BENJAMIN, 1994, p. 114)
}

Essa perda da capacidade de transmitir experiências, de acordo com o autor, teria um marco de origem na geração entre 1914 e 1918, a qual se encontrava mais pobre em experiências comunicáveis, devido aos traumas vivenciados nos campos de batalha, no contexto da $1^{\text {a }}$ Guerra Mundial.

Uma geração que ainda fora à escola num bonde puxado por cavalos viu-se abandonada, sem teto, numa paisagem diferente em tudo, exceto nas nuvens, e em cujo centro, num campo de forças de correntes e explosões destruidoras, estava o frágil e minúsculo corpo humano. (BENJAIMN, 1994, p. 115).

Na contramão do comportamento saudosista do personagem Gil, as pessoas com quem convive, sua noiva e os pais, caracterizam-se por um comportamento típico dos indivíduos inseridos no contexto moderno, que experimentam o que Benjamin define como pobreza de experiência: "não se deve imaginar que os homens aspirem a novas experiências. Não, eles aspiram a libertar-se de toda experiência, aspiram a um mundo em que possam ostentar tão pura e tão claramente sua pobreza externa e interna" (BENJAMIN, 1994, p. 118)

DOI: $10.17851 / 2179-8478.0 .9 .32-40$ 
Os personagens em questão não possuem capacidade de discutir questões políticas, democráticas e sociais, acreditando que somente seu ponto de vista é o correto. Não há, em suas vidas, espaço para maiores reflexões. "Ficamos pobres. Abandonamos uma depois da outra todas as peças do patrimônio humano" (BENJAMIN, 1994, p. 119). É o que Benjamin definirá como o declínio da aura no contexto moderno.

Não somente a obra de arte perdeu seu valor de culto, substituído pelo valor de exposição, como quem perde com esta realidade é o próprio homem, que tem sua existência transformada e reorganizada em um mundo moderno, sem espaço para reflexões e, como visto anteriormente, sem tempo ou hábito para intercambiar experiências.

Avaliando o contexto da sociedade moderna, é observável que o modo de produção capitalista gerou mudanças na forma de se perceber a arte. A reprodutibilidade técnica da obra de arte gera como consequência a perda da sua "aura". Conforme Benjamin, a obra perdeu sua singularidade. "Mesmo na reprodução mais perfeita, um elemento está ausente: o aqui e agora da obra de arte, sua existência única, no lugar em que ela se encontra" (BENJAMIN, 1994, p. 167). De certa forma, o que se percebe na busca do personagem de Gil é novamente encontrar-se neste lugar único, no caso o tempo em que viveram os escritores e artistas em quem ele tanto se inspira e admira. Em suma, para o autor, a definição de aura é:

[...] uma figura singular, composta de elementos espaciais e temporais: a aparição única de uma coisa distante, por mais perto que ela esteja. Observar, em repouso, numa tarde de verão, uma cadeia de montanhas no horizonte, ou um galho, que projeta sua sombra sobre nós, significa respirar a aura dessas montanhas, desse galho. (BENJAMIN, 1994, p. 170).

Conforme o autor, o declínio da aura se dá por meio de fatores sociais específicos, como a intensa preocupação em "fazer as coisas ficarem mais próximas". Benjamin ressalta: "Cada dia fíca mais irresistível a necessidade de possuir o objeto, de tão perto quanto possível, na imagem, ou antes, na sua cópia, na sua reprodução" (1994, p.170). É a ânsia de possuir os objetos e não de admirá-los. De acordo com o autor, o começo do declínio da aura da obra de arte se dá com a fotografia, quando "o valor de culto começa a recuar, em todas as frentes, diante do valor de exposição" (BENJAMIN, 1994, p.174). Perde-se cada vez mais o valor de eternidade e a arte passa a servir ao propósito de manipular e controlar as massas.

Com a reprodução da arte em série, de forma rápida e facilitada, acaba por atrofiar-se no ser humano a capacidade de exercitar seu próprio pensamento. Benjamin afirma que "a constante disponibilidade de lembrança voluntária, discursiva, favorecida pelas técnicas de reprodução, reduz o âmbito da imaginação" (BENJAMIN, 1989, p.138). A perda da aura associa-se a esta atrofia do pensamento. De acordo com o autor:

[...] esta aura em torno do objeto corresponde à própria experiência que se cristaliza em um objeto de uso sob a forma de exercício. Os dispositivos, com que as câmeras e as aparelhagens análogas posteriores foram equipadas, ampliaram o alcance da mémorie volontaire; por meio dessa aparelhagem, eles possibilitam fixar um acontecimento a qualquer momento, em som e imagem, e se transformam assim em uma importante conquista para a sociedade, na qual o exercício se atrofia. (BENJAMIN, 1989, p. 137). 
A velocidade e as possibilidades proporcionadas pela ascensão da tecnologia têm, neste sentido, seu contraponto. Até que nível o ser humano ainda é capaz de exercitar a própria inteligência, criatividade e reflexão? Para determinados indivíduos, como exemplo do personagem Gil, instaura-se uma crise existencial, quanto à identificação com o presente. De acordo com Benjamin, "o que torna insaciável o prazer do belo é a imagem do mundo primitivo, que Baudelaire chama de velado por lágrimas de nostalgia" (BENJAMIN, 1989, p.139).

\section{Menos experiência, mais vivência}

Conforme Benjamin há um declínio da memória na vida moderna dos seres humanos, em que a vivência passa a substituir a experiência, o que altera todo um comportamento social. A vivência gera a memória voluntária, de características efêmeras, baseada na informação - produto da sociedade moderna. "[...] a memória voluntária e as informações sobre o passado, por ela transmitidas, não guardam nenhum traço dele" (1989, p.106). Enquanto isso vai ficando mais obscura a memória involuntária, fruto de experiências, de características definitivas de aprendizado na vida do ser humano. De acordo com Benjamin, "a exclusão da informação no âmbito da experiência se explica ainda pelo fato de que a primeira não se integra à "tradição"” (BENJAMIN, 1989, p.107).

É fato que, com a evolução tecnológica e principalmente dos meios de comunicação de massa, a experiência dos homens se transformou no que apenas é possível apreender no dia-a-dia atarefado do trabalhador, que mesmo em seus momentos de lazer, ainda constitui um consumidor em potencial, seja de produtos ou de informações. Toda uma tradição do pensamento e reflexão se altera com a velocidade com que andam os ponteiros das novas gerações. É a sociedade que enfrenta Gil e, ao mesmo tempo, a amante Adriana. Ambos não compreendem porque não se sentem satisfeitos em compartilhar vivências. Para Benjamin:

\footnotetext{
Há uma rivalidade histórica entre as diversas formas da comunicação. $\mathrm{Na}$ substituição da antiga forma narrativa pela informação, e da informação pela sensação reflete-se a crescente atrofia da experiência. Todas essas formas, por sua vez, se distinguem da narração, que é uma das mais antigas formas de comunicação. Esta não tem a pretensão de transmitir um acontecimento, pura e simplesmente (como a informação o faz); integra-o à vida do narrador, para passá-lo aos ouvintes como experiência. Nela ficam impressas as marcas do narrador como os vestígios das mãos do leiro no vaso da argila. (BENJAMIN,1989, p. 107).
}

Benjamin se baseia na oposição dos conceitos de Erfahrung e Erlebnis, que podem ser “traduzidas respectivamente como 'experiência' (real ou acumulada, sem intervenção da consciência) e 'vivência' (experiência vivida, evento assistido pela consciência)" (1989, p. 146). De acordo com Leandro Konder (apud Benjamin, 1989, p. 146):

Erfahrung é o conhecimento obtido através de uma experiência que se acumula, que se prolonga, que se desdobra, como numa viagem; o sujeito integrado numa comunidade dispõe de critérios que lhe permitem ir sedimentando as coisas com o 
tempo. Erlebnis é a vivência do indivíduo privado, isolado, é a impressão forte, que precisa ser assimilada às pressas, que produz efeitos imediatos. (KONDER apud BENJAMIN, 1989, p. 146)

Neste sentindo, compreende-se que Gil e também Adriana buscam um mundo em que o mais importante seja a experiência e não a vivência. Os personagens pretendem viver intensamente a reflexão, junto aos artistas e aos momentos históricos para os quais têm a oportunidade de se transportar.

\section{A indiferença de ser apenas um a mais}

A sociedade tornou-se um acumulado de pessoas, um todo amorfo, o qual Benjamin define como multidão. Uma das principais características destes indivíduos aglomerados em seu dia a dia é a indiferença de uns pelos outros, motivo de depressão e descontentamento. As pessoas se sentem solitárias, justamente por viverem em tamanha multidão, nas grandes metrópoles. Neste contexto, Benjamin contextualiza duas figuras: o homem da multidão, um anônimo sujeito, que seguia as normas; e o flâneur, indivíduo isolado, e reflexivo observador da multidão. É neste grupo que podemos classificar os amantes do passado, Gil e Adriana.

Havia o transeunte, que se enfia na multidão, mas havia também o flâneur, que precisa de espaço livre e não quer perder sua privacidade. Que os outros se ocupem de seus negócios: no fundo, o indivíduo só pode flanar se, como tal, já se afasta da norma. (BENJAMIN, 1989, p. 122).

A multidão trata-se de um coletivo composto de indivíduos indiferentes uns aos outros. De acordo com Engels apud Benajmin, 1989, p. 115:

[...] o único acordo tácito entre eles é o de que cada um conserve o lado da calçada à sua direita, para que ambas as correntes da multidão, de sentidos opostos, não se detenham mutuamente; e, no entanto, não ocorre a ninguém conceder ao outro um olhar sequer. Essa indiferença brutal, esse isolamento insensível de cada indivíduo em seus interesses privados, avultam tanto mais repugnantes e ofensivos quanto mais estes indivíduos se comprimem num exíguo espaço.

Em sua obra As Flores do Mal, de 1857, o escritor Charles Baudelaire refletia em seus poemas a melancolia da efervescida vida das multidões em Paris, cenário do filme de Woody Allen. "A massa era o véu agitado através do qual Baudelaire via Paris. Sua presença caracteriza um dos poemas mais célebres de As Flores do Mal", afirma Benjamin (1998, p.117). Tal poema, intitulado 'A uma Passante', reflete a realidade da multidão na capital francesa, em meados do século XIX:

A rua em torno era um frenético alarido.

Toda de luto, alta e sutil, dor majestosa,

Uma mulher passou, com sua mão suntuosa

Erguendo e sacudindo a barra do vestido. 


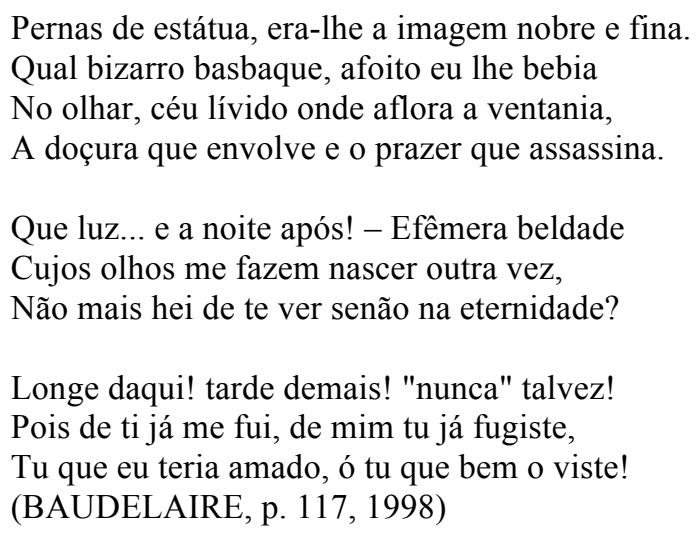

O poema de Baudelaire reflete exatamente a realidade de uma multidão de indivíduos que não têm mais a oportunidade de intercambiar-se. A realidade de uma sociedade apressada, que não tem tempo de apaixonar-se, de refletir, de sonhar. Em tal contexto, o que resta para o indivíduo, em muitos casos, é a depressão de exaltar um passado, presente que não foi seu.

Existe, na multidão, uma tendência à uniformidade de costumes, hábitos, modos de ser, agir e pensar. As pessoas que não se adaptarem à realidade, automaticamente estarão excluídas - e assim devem se sentir, como é o caso de Gil, em seu tempo.

Em determinada cena do filme, quando visitam novamente uma exposição em um museu, Inez e o casal Paul e Carol demonstram estar inseridos nos assuntos de arte. Paul, especialmente, se mostra um tanto "pedante" (termo utilizado pela personagem de uma guia turística no filme), explanando sobre todas as obras, mesmo sem conhecer a história oficial. $\mathrm{O}$ deslocamento de Gil, neste momento, fica muito perceptível, uma vez que quando ele traz à tona informações verdadeiras e complementares ao discurso de Tom, é sequer levado a sério pelos demais.

\section{Conclusão}

Qual o melhor tempo para se viver? O tempo de nossos pais, avós e antepassados, ou de nossos filhos, netos e descendentes? O tempo do outro?

É o passadismo que Woody Allen retrata em Meia Noite em Paris, consequência de uma vontade comum a muitas pessoas: a de viver em um período que se tem a impressão de que se era mais feliz, de que se poderia ser. Uma época no qual eram compartilhadas experiências, ao invés de meramente desfrutadas vivências; onde as pessoas não sentiam-se estranhas em seu próprio tempo, vivendo a angustia de ser apenas mais um em meio à multidão; e, principalmente, uma época em que a aura da obra da arte, sua essência e autenticidade esteve viva, presente, real.

O tempo do homem não serve para ele. A depressão, característica de quem vive no passado, é uma constante na existência moderna, uma vez que encarar a própria realidade é desanimador.

É como certa vez escreveu em seu romance $O$ Grande Gatsby, clássico da década de 1920, o próprio F. Scott Fitzgerald, com quem o personagem Gil tem o prazer de se encontrar em sua viagem no tempo: "E assim prosseguimos, barcos contra a corrente, arrastados incessantemente para o passado" (2013, p. 218). A busca é por algo que, de fato não existe. 
Não na realidade, mas sim em um sonho, em um ideal. Enquanto tudo o que há disponível, seja ele qual for, é o presente.

\section{Referências bibliográficas}

BASCOV, I. "Meia-noite em paris": sempre é tempo. Revista Veja. Coluna Ricardo Setti. 23 jun. 2013. Disponível em: <http://veja.abril.com.br/blog/ricardo-setti/dica-de-leitura/aindanao-viu-meia-noite-em-paris-de-woody-allen-e-o-que-esta-esperando-para-ir-atras-do-bluray-ou-do-dvd/ > acesso em 11/12/13.

BAUDELAIRE, Charles. As flores do mal. Trad. Ivan Junqueira. Rio de Janeiro: Nova Fronteira, 1998.

BENJAMIN, W. Magia e técnica, arte e política. Trad. Sergio Paulo Rouanet. 7. ed. São Paulo: Brasiliense, 1994. V. 1.

. Charles Baudelaire: um lírico no auge do capitalismo. Trad. José C. M. Barbosa e Hemerson A. Baptista. São Paulo: Brasiliense, 1989. V. 3.

FITZGERALD, F. Scott. O grande Gatsby. Trad. Roberto Muggiati. 6. ed. Rio de Janeiro: Record, 2013. 272 p.

LIMA, L. (Org.). Teoria da literatura em suas fontes. Rio de Janeiro: Civilização Brasileira, 2002. Vol. 2.

Meia Noite em Paris. Disponível em: <http:/www.adorocinema.com/filmes/filme-178300/> Acesso em 11/12/13. Sinopse e detalhes.

Meia-noite em Paris. Disponível em: <http://www.imdb.com/title/tt1605783/> Acesso em $11 / 12 / 13$. 